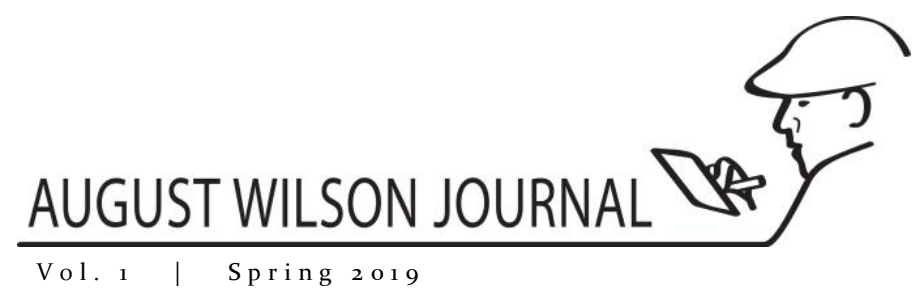

\title{
Erratum: Ridley, Leticia. "Stage Review of Gem of the Ocean." August Wilson Journal doi:https://doi.org/10.5195/awj.2019.22.
}

\section{Michael J. Downing} Editor

In Ridley, Leticia. "Stage Review of Gem of the Ocean." August Wilson Journal doi:https://doi.org/10.5195.awj.2019.22, author Leticia Ridley's credentials were updated from master's candidate to doctoral candidate. 